Supporting Information:

A scientist's guide to buying a 3D printer: how to choose the right printer for your laboratory.

\author{
Joshua J Tully ${ }^{l}$, Gabriel N Meloni ${ }^{1^{*}}$
}

${ }^{1}$ Department of Chemistry, University of Warwick, Coventry, CV4 7AL, United Kingdom

\title{
Contents:
}

$\begin{array}{lc}\text { SI.1 Glossary of Terms } & \text { S2 }\end{array}$

$\begin{array}{lc}\text { SI.2 Effect of Layer Height } & \text { S4 }\end{array}$

$\begin{array}{ll}\text { SI.3 Effect of Infill } & \text { S5 }\end{array}$

SI.4 Effect of Perimeters

$\begin{array}{lr}\text { SI.5 Comparison of FDM Printers } & \text { S7 }\end{array}$

$\begin{array}{lr}\text { SI.6 Comparison of VP Printers } & \text { S8 }\end{array}$ 


\section{SI.1 Glossary of Terms}

\section{General Terms}

Additive Manufacturing: The process of building a model up layer by layer by adding material.

3D Printing: The process of building a 3D model, usually layer by layer.

Layer Height: The thickness of each layer in the Z Axis.

Support: Structures that are not part of the original model and are created to improve the printability and removed after printing.

STL: Stereolithography file types that are standard for storing 3D models.

\section{Fusion Deposition Modelling}

FDM: Fusion Deposition Modelling, depositing hot filament to form an object layer-by-layer. FFF: Synonymous with FDM.

Thermoplastic: The feedstock of FDM printers.

Filament: The feedstock of FDM printers, a long continuous strand of thermoplastic.

Nozzle: Opening of a fixed diameter through which the filament is extruded, the size of which determines the width of the extrusion.

Hot End: The area in which the filament is melted before being pushed through the nozzle.

Part Cooling Fans: Fans used to cool extruded filament after extrusion.

Print Head: The carriage that contains the hot end, nozzle, part cooling fans, allowing it to move in one or two axes.

Build Platform: The base on which the 3D print is built up, the size of this determines the maximum print size. The build platform usually moves in one axis.

Dual Extrusion: The ability of an FDM printer to print in multiple plastics for a single print.

\section{FDM Parts/Slicer Settings}

Infill: The \% solid the middle of the print is.

Infill Pattern: The shape of the infill.

Top Layers: The number of solid layers the printer completes after finishing the infill.

Bottom Layers: The number of solid layers the printer completes before starting the infill.

Perimeters: The number of "laps" round a prints exterior the printer completes before starting infill. 


\section{Vat Photopolymerisation}

VP: Vat Photopolymerisation, the technique of selectively polymerising a vat of photopolymer resin to create a solid object.

DLP: Direct Light Processing, a VP printer with the light source being a UV LEDs, selectively masked by a digital display.

SLA: Stereolithography, a VP printer with the light source being a UV diode laser moved using a mirror galvanometer.

Mirror Galvanometer: A mirror that can have its angle changed electronically.

UV: Ultra-violet light with a wavelength shorter than violet, used to initiate photopolymerisation.

Photopolymer: A polymer, which on exposure to UV polymerises to form a solid object. 


\section{SI.2 Effect of Layer Height}

Layer height is one of the key settings in FDM slicers, with knock on effects ranging from surface finish to print time. Figure S2 shows the difference in surface quality for a range of layer heights.

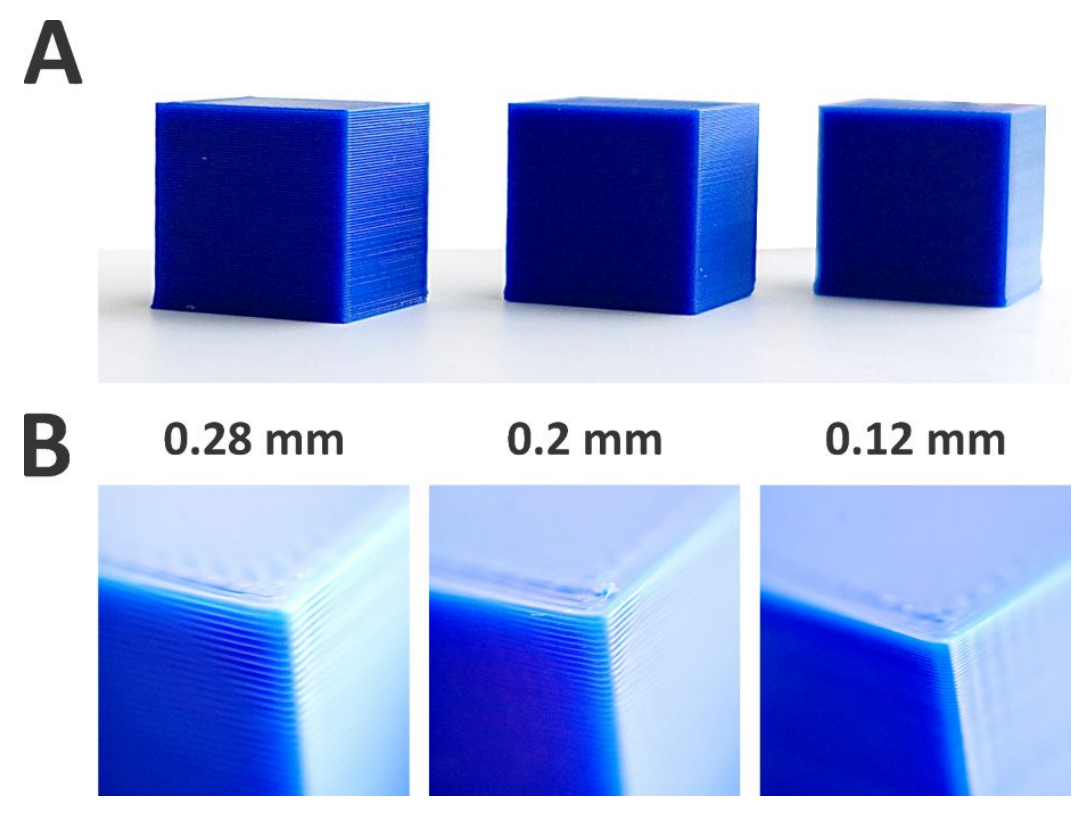

Figure S2: Three $10 \mathrm{~mm}$ cubes printed in PLA on a modified Creality Ender 3 at three different layer heights $(0.28,0.2,0.12 \mathrm{~mm})$. Total print times were 20, 30, and 50 minutes, respectively.

It can be seen from Figure S1 that the layer height (effectively the Z resolution) can be selected, with small heights taking longer to print, but capturing more detail, and reducing surface roughness. 


\section{SI.3 Effect of Infill}

The infill percentage selected in the slicer controls the density of the final printed piece, the most significant effect of changing infill is the change in strength of the resultant print. Figure S2 compares a top-view cross section for three different infill percentages.

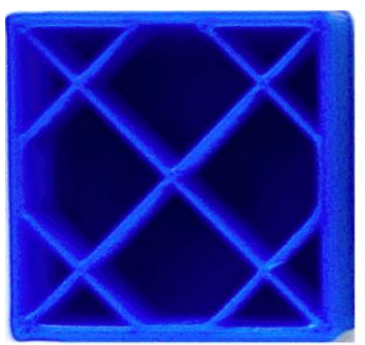

$10 \%$

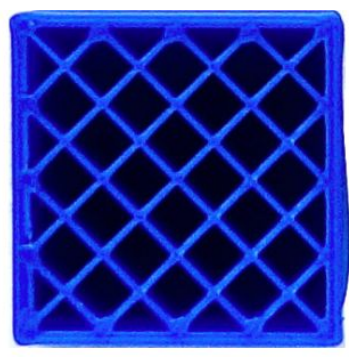

$25 \%$

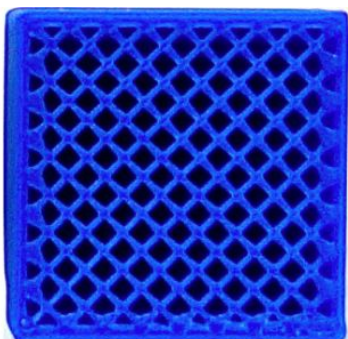

$50 \%$

Figure S3: Top-view cross sections of three $10 \mathrm{~mm}$ cubes printed in PLA on a modified Creality Ender 3 at three different infill densities (10,25 and 50\%). Total print times at $0.28 \mathrm{~mm}$ layer height were 18, 20, and 28 minutes, respectively. 


\section{SI.4 Effect of Walls}

Changing the number of walls effectively controls how many "laps" the 3D printer makes around the outside of the object, more walls increases the print time, but will also increase the strength and water-tightness of the piece. Figure S3 compares a top-down cross section for three different amounts of walls.

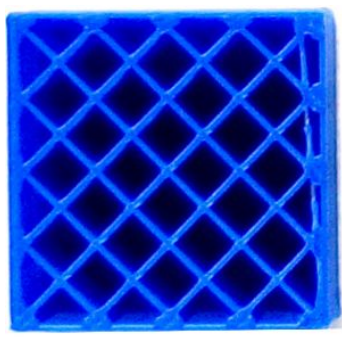

1 wall

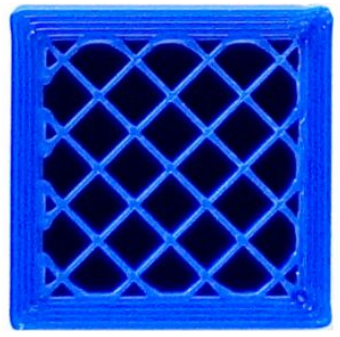

5 walls

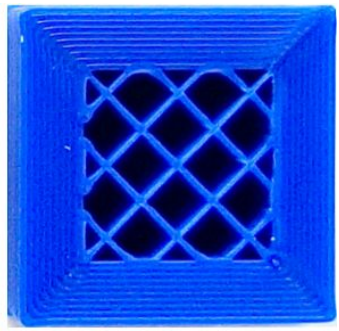

10 walls

Figure S3: Top-view cross sections of three $10 \mathrm{~mm}$ cubes printed in PLA on a modified Creality Ender 3 at three different numbers of walls $(1,5,10)$. Total print times at $0.28 \mathrm{~mm}$ layer height and $25 \%$ infill were 20, 28, and 38 minutes, respectively. 


\section{SI.5 Comparison of FDM Printers}

Table S1: Comparison of specifications and prices for the most commonly available commercial FDM 3 D printers (Compiled July 2020).

\begin{tabular}{|c|c|c|c|c|c|}
\hline Name & $\begin{array}{c}\text { Printing volume } \\
(\mathrm{cm})\end{array}$ & $\begin{array}{c}\text { Pre- } \\
\text { assembled }\end{array}$ & $\begin{array}{c}\text { Dual } \\
\text { Extrusion }\end{array}$ & $\begin{array}{c}\text { Bed } \\
\text { Levelling }\end{array}$ & Price (f) \\
\hline \multicolumn{6}{|c|}{ Prusa Research, Czech Republic } \\
\hline $\begin{array}{l}\text { Original Prusa } \\
\text { Mini }\end{array}$ & $18 \times 18 \times 18$ & No & No & Automatic & 320 \\
\hline $\begin{array}{c}\text { Original Prusa } \\
\text { MK3S }\end{array}$ & $25 \times 21 \times 21$ & Optional & $\begin{array}{l}\text { Can be } \\
\text { added. }\end{array}$ & Automatic & $700 / 900$ \\
\hline \multicolumn{6}{|c|}{ Lulzbot, USA } \\
\hline $\begin{array}{c}\text { Taz } \\
\text { Workhorse }\end{array}$ & $28 \times 28 \times 28.5$ & No & No & Automatic & 2,300 \\
\hline Taz Pro & $28 \times 28 \times 28.5$ & No & Yes & Automatic & 3,900 \\
\hline \multicolumn{6}{|c|}{ Ultimaker, Netherlands } \\
\hline Ultimaker $2+$ & $22 \times 22 \times 20$ & Yes & No & Manual & 1,850 \\
\hline Ultimaker 3 & $22 \times 22 \times 20$ & Yes & Yes & Automatic & 2,900 \\
\hline Ultimaker S5 & $33 \times 24 \times 30$ & Yes & Yes & Automatic & 5,390 \\
\hline \multicolumn{6}{|c|}{ Wanhao, China } \\
\hline $\begin{array}{c}\text { Duplicator D9 } \\
300 \mathrm{MK} 2\end{array}$ & $30 \times 30 \times 40$ & No & No & Automatic & 550 \\
\hline \multicolumn{6}{|c|}{ Creality, China } \\
\hline Ender 3 Pro & $22 \times 22 \times 25$ & No & No & Manual & 200 \\
\hline
\end{tabular}




\section{SI.6 Comparison of VP Printers}

Table S5: Comparison of specifications and prices for the most commonly available commercial VP 3D printers (Compiled July 2020).

\begin{tabular}{|c|c|c|c|c|c|}
\hline Name & $\begin{array}{c}\text { Printing volume } \\
(\mathrm{cm})\end{array}$ & $\begin{array}{c}\text { Pre- } \\
\text { assembled } \\
\end{array}$ & Technology & $\begin{array}{l}\text { Resin } \\
\text { Choice }\end{array}$ & Price (f) \\
\hline \multicolumn{6}{|c|}{ Prusa Research, Czech Republic } \\
\hline $\begin{array}{l}\text { Original Prusa } \\
\text { SL1 }\end{array}$ & $12 \times 6.8 \times 15$ & No & DLP & Any & 1,500 \\
\hline $\begin{array}{l}\text { Original Prusa } \\
\text { Washing and } \\
\text { Curing } \\
\text { Machine } \\
\text { (CW1) }\end{array}$ & N/A & $\mathrm{N} / \mathrm{A}$ & $\mathrm{N} / \mathrm{A}$ & $\mathrm{N} / \mathrm{A}$ & 630 \\
\hline \multicolumn{6}{|c|}{ Form Labs, USA } \\
\hline Form 3 & $14.5 \times 14.5 \times 18.5$ & Yes & SLA & $\begin{array}{c}\text { Formlabs } \\
\text { Only }\end{array}$ & 3,500 \\
\hline Form $3 \mathrm{~L}$ & $33.5 \times 20 \times 30$ & Yes & SLA & $\begin{array}{c}\text { Formlabs } \\
\text { Only }\end{array}$ & 9,600 \\
\hline Form Wash & $\mathrm{N} / \mathrm{A}$ & $\mathrm{N} / \mathrm{A}$ & $\mathrm{N} / \mathrm{A}$ & $\mathrm{N} / \mathrm{A}$ & 530 \\
\hline Form Cure & $\mathrm{N} / \mathrm{A}$ & $\mathrm{N} / \mathrm{A}$ & N/A & N/A & 750 \\
\hline \multicolumn{6}{|c|}{ Anycubic, China } \\
\hline $\begin{array}{l}\text { Anycubic } \\
\text { Photon }\end{array}$ & $11.5 \times 6.5 \times 11.5$ & Yes & DLP & Any & $£ 200$ \\
\hline
\end{tabular}

